Priscylla Sayuri MIYA ${ }^{1}$

Thiesa Butterby SOLER ${ }^{1}$

Sandra Helena Ramires

CORREA $^{2}$

Marcelo Alcindo de Barros

Vaz GUIMARÃES ${ }^{1}$

Correspondência para:

Priscylla Sayuri Miya

Endereço: Rua Duque de Caxias, 503, apto

51 - Campinas/SP 13015-310

e-mail: pry.sayuri@ig.com.br

Recebido para publicação: 14/10/2005 Aprovado para publicação: 23/08/2007

\title{
Avaliação do espermograma de leões africanos (Panthera leo, Linnaeus, 1758), mantidos na Fundação Parque Zoológico de São Paulo
}

1 - Departamento de Reprodução Animal da Faculdade de Medicina Veterinária e

Zootecnia da Universidade de São Paulo, São Paulo-SP

2 - Fundação Parque Zoológico de São Paulo, São Paulo-SP

Resumo

O presente estudo teve por objetivo avaliar o espermograma de um grupo de leões africanos mantidos em cativeiro na Fundação Parque Zoológico de São Paulo, como um aspecto a ser considerado na avaliação do potencial reprodutivo para a aplicação de técnicas de reprodução assistida. Foram submetidos a eletroejaculação 14 exemplares machos, adultos de Leão Africano, utilizando-se o método da eletroejaculação. Logo após a colheita, cada uma das 13 amostras obtidas foi examinada quanto ao volume, $\mathrm{pH}$ e aspecto geral, seguida pela avaliação da motilidade, movimento progressivo, índice de motilidade espermática e concentração. Uma alíquota do ejaculado foi fixada em solução de formol-salina a $10 \%$ e analisado em câmara úmida ao microscópio de interferência de fase, para o estudo dos aspectos morfológicos, classificando as alterações dos espermatozóides em defeitos maiores e menores. Os resultados foram: volume 5,83 \pm $3,35 \mathrm{ml}$; concentração 11,62 $\pm 14,51 \times 10^{6}$ espermatozóides $/ \mathrm{ml}$; motilidade total $73,85 \pm 11,02 \%$; motilidade progressiva 3,35 \pm 0,63 ; índice de motilidade espermática $70,42 \%, \mathrm{pH} 8,1 \pm 0,5$; defeitos maiores 38,12 $\pm 19,41 \%$; defeitos menores 17,43 $\pm 10,36 \%$; defeitos totais $55,55 \pm 19,30 \%$. Os defeitos maiores mais freqüentes foram gota citoplasmática proximal, peça intermediária dobrada com gota citoplasmática e peça intermediária dobrada. A cauda dobrada foi o defeito menor mais encontrado.

\section{Introdução}

Muitas espécies animais tiveram seu número de indivíduos bastante reduzido pela destruição de seu habitat natural, caça esportiva e predatória ou por outras interferências humanas. Estas populações reduzidas geralmente estão isoladas em pequenas áreas preservadas, resultando em cruzamentos com maiores graus de consangüinidade, tornando a homozigose mais freqüente, assim como as doenças hereditárias, diminuindo a capacidade de sobrevivência dos animais e reduzindo a eficiência reprodutiva.

Para evitar que a diversidade genética seja tão reduzida, é necessário que se desenvolvam programas de conservação, além de estudos relativos à otimização do desempenho reprodutivo dos animais selvagens em cativeiro. Para tanto, técnicas de reprodução assistida, utilizadas em animais domésticos, podem ser adaptadas e aplicadas a espécies silvestres. Técnicas como colheita, avaliação e congelamento de sêmen, transferência de embriões, indução hormonal de estro e da ovulação, podem representar significativo aumento do sucesso reprodutivo de uma espécie, e simultaneamente, permitir a manutenção da variabilidade genética de uma população. ${ }^{1}$

A formação de bancos de material genético criopreservado é uma importante ferramenta para alcançar estes objetivos e o 
primeiro passo é colher e conhecer melhor o material a ser preservado, para que se possa desenvolver metodologia que permita que esta preservação mantenha a viabilidade deste material. A criopreservação bem sucedida de sêmen é uma das chaves para a manutenção da diversidade genética das espécies ameaçadas. ${ }^{2}$

O Leão Africano (Panthera leo) é um mamífero pertencente à Família Felidae, pesando de 120 a $200 \mathrm{~kg}$ e com comprimento total de 2,6 a 3,3 metros $^{3}$, e são os únicos felinos que apresentam um sistema social altamente estruturado, denominado "pride", de caráter matrilocal ${ }^{4}$. Este é formado por um grupo de 2-18 fêmeas geneticamente aparentadas e suas crias, sem que haja relação de dominância entre elas. ${ }^{5}$ A sociedade é liderada temporariamente por um macho ou por uma coalizão de 2-9 machos, também sem dominância entre si, até que uma nova coalizão assuma o controle do "pride" e os expulse. ${ }^{4}$

Originalmente, os leões eram encontrados da África até o Sudoeste Asiático, no Oeste Europeu e no Leste da Índia. Em muitos locais eles foram extintos e atualmente o leão africano é encontrado no Leste e Sul da África, com um número pequeno de indivíduos no Oeste Africano. A maioria dos animais vive em áreas protegidas, em um número estimado de 30 a 100 mil indivíduos. ${ }^{6}$

Os principais fatores que ameaçam a sobrevivência dos leões são a diminuição do habitat e a caça. Em conseqüência destas ameaças, o leão está classificado como espécie vulnerável de acordo com a União Internacional para a Conservação da Natureza - IUCN. ${ }^{6}$

Devido a esses fatores, torna-se importante determinar formas de reprodução assistida eficientes, para se evitar que o número de leões diminua a tal ponto que a extinção torne-se inevitável por falta de variabilidade genética.

O leão africano também pode ser considerado como animal modelo para o desenvolvimento de técnicas de reprodução assistida para espécies de grandes felinos brasileiros como a onça-pintada (Panthera onca) e a suçuarana (Puma concolor).

O primeiro passo para o desenvolvimento de programas de reprodução assistida é buscar a identificação de potenciais reprodutores. Neste contexto, a avaliação do sêmen se constitui no primeiro passo para esta identificação.

Este estudo teve por objetivo avaliar e caracterizar o espermograma de leões africanos mantidos em cativeiro na Fundação Parque Zoológico de São Paulo.

\section{Material e Método}

Foram submetidos a eletroejaculação 14 exemplares machos, adultos de Leão Africano, pertencentes à Fundação Parque Zoológico de São Paulo (FPZSP). Os animais apresentavam-se hígidos e sexualmente ativos.

As colheitas foram realizadas após a anestesia dos animais, utilizando-se as associações dos fármacos cloridrato de cetamina, $10,0 \mathrm{mg} / \mathrm{kg}\left(\right.$ Vetaset $^{\circledR}$, Fort Dodge do Brasil, São Paulo, SP) e cloridrato de xilazina, na dose de $1,0 \mathrm{mg} / \mathrm{kg}$ (Rompun ${ }^{\circledR}$, Bayer do Brasil, São Paulo, SP), ambos por via intramuscular. Após a contenção química, as amostras foram colhidas por eletroejaculação como uso de eletrodo retal bipolar conectado ao aparelho gerador de eletrochoques (Torjet ${ }^{\circledR}$, Eletrovet, São Paulo, SP), utilizando-se o protocolo proposto por Howard ${ }^{7}$. Este protocolo constitui-se de 80 eletrochoques, divididos em séries de 10 eletrochoques em cada voltagem, iniciandose a primeira série com 4,5 e 6 volts, a segunda com 5, 6 e 7 volts e a terceira, 6 e 7 volts. Cada alíquota de sêmen obtida foi analisada em separado e no fim do procedimento de cada animal, eram combinadas.

Imediatamente após a colheita, cada alíquota foi examinada macroscopicamente quanto ao volume, aspecto e coloração. Em seguida ocorreu a análise sob microscopia óptica (BX50 Olympus ${ }^{\circledR}$, sob aumento de 400 vezes) quanto a motilidade total (porcentagem de espermatozóides móveis) 
e motilidade progressiva (espermatozóides que apresentam deslocamento progressivo), utilizando-se o critério de Howard ${ }^{7}$. A motilidade progressiva é classificada subjetivamente de 1 a 5 , sendo 1 quando poucas células apresentam este tipo de movimento e 5 quando quase todas se movem de forma progressiva. Através da porcentagem de espermatozóides móveis e do valor atribuído a motilidade progressiva, foi calculado o Índice de Motilidade Espermática (IME), segundo Howard ${ }^{7}$. Segundo o autor citado, este é um método mais preciso para avaliar a taxa de motilidade espermática de forma global, com igual ênfase na porcentagem de motilidade e motilidade progressiva. Para tanto, utilizou-se a seguinte fórmula: IME = $[\%$ motilidade total $+(20 \times$ motilidade progressiva)] $/ 2$.

Foi utilizada uma gota de sêmen para mensuração do $\mathrm{pH}$ em fita reagente comercial (Labstick, Merck ${ }^{\circledR}$ ). A concentração foi calculada com o uso de câmara hematimétrica de Newbauer, estando o sêmen diluído na proporção 1:200.Uma alíquota do ejaculado combinado foi fixada em uma solução de formol-salina a 10\%, na proporção 1:1. Esse material, após montagem úmida em lâmina de vidro, foi analisado ao microscópio de contraste de fase sob aumento de 1000 vezes (Leitz Dialux $20^{\circledR}$ ), para o estudo das características morfológicas, sendo contadas 200 células por amostra. A avaliação das alterações morfológicas espermáticas foi realizada no Laboratório de Andrologia do Departamento de Reprodução Animal da Faculdade de Medicina Veterinária e Zootecnia da Universidade de São Paulo.

Foram efetuadas análises estatísticas descritivas, quais sejam: média, desvio- padrão e intervalo de confiança para os resultados encontrados nas análises.

\section{Resultado e Discussão}

Foram realizadas 21 tentativas de eletroejaculação em 14 animais, sendo que em 13 oportunidades foram obtidas amostras de sêmen. Os resultados dos espermogramas encontram-se descritos na tabela 1.

O Índice de Motilidade Espermática calculada para o grupo foi de $70,42 \%$.

Os resultados obtidos para motilidade total e movimento progressivo, encontramse muito próximos aos descritos no único trabalho encontrado na literatura, quais sejam, $72,0 \pm 4,6 \%$ de motilidade espermática total e 3,6 $\pm 0,2$ de motilidade progressiva. ${ }^{7}$

A concentração espermática e o volume, apresentaram marcado desvio padrão. Este aspecto deve-se, provavelmente, ao fato de haver muita variação de respostas aos estímulos elétricos, entre indivíduos e entre colheitas. $\mathrm{Na}$ literatura encontramos valores de $40,1 \pm 8,0 \times 10^{6} \mathrm{sptz} / \mathrm{ml}$ e 11,0 $\pm 1,2 \mathrm{ml}$ para concentração e volume, respectivamente. ${ }^{7}$ Além das variações inerentes ao método, outro aspecto a ser considerado na análise comparativa dos resultados obtidos para o volume e concentração, é o fato de interrompermos os procedimentos assim que fosse obtida a amostra, enquanto Howard ${ }^{7}$, prosseguia até o esgotamento do animal. Por outro lado, estas discrepâncias também podem ser imputadas às diferentes características do manejo das instituições mantenedoras, incluindo-se aí a dieta alimentar.

O pleiomorfismo espermático em carnívoros apresenta uma ocorrência espécie específica, sendo que determinadas espécies

Tabela 1 - Valores médios e respectivos desvios-padrão dos espermogramas do grupo de leões africanos (Panthera leo), mantidos na Fundação Parque Zoológico de São Paulo, 2004

\begin{tabular}{lllllllll}
\hline & $\begin{array}{l}\text { Volume } \\
(\mathrm{ml})\end{array}$ & $\begin{array}{l}\text { Concentração } \\
(\mathrm{sptz \times 10} / \mathrm{ml})\end{array}$ & $\begin{array}{l}\text { Motilidade } \\
\text { Total (\%) }\end{array}$ & $\begin{array}{l}\text { Motilidade } \\
\text { Progressiva } \\
(1-5)\end{array}$ & $\begin{array}{l}\text { pH } \\
\text { Maiores (\%) }\end{array}$ & $\begin{array}{l}\text { Defeitos } \\
\text { Menores (\%) }\end{array}$ & $\begin{array}{l}\text { Defeitos } \\
\text { Totais (\%) }\end{array}$ \\
\hline Média (n=13) & 5,83 & 11,62 & 73,85 & 3,35 & 8,1 & 38,12 & 17,43 & 55,55 \\
Desvio Padrão & 3,35 & 14,51 & 11,02 & 0,63 & 0,5 & 19,41 & 10,36 & 19,30 \\
\hline
\end{tabular}




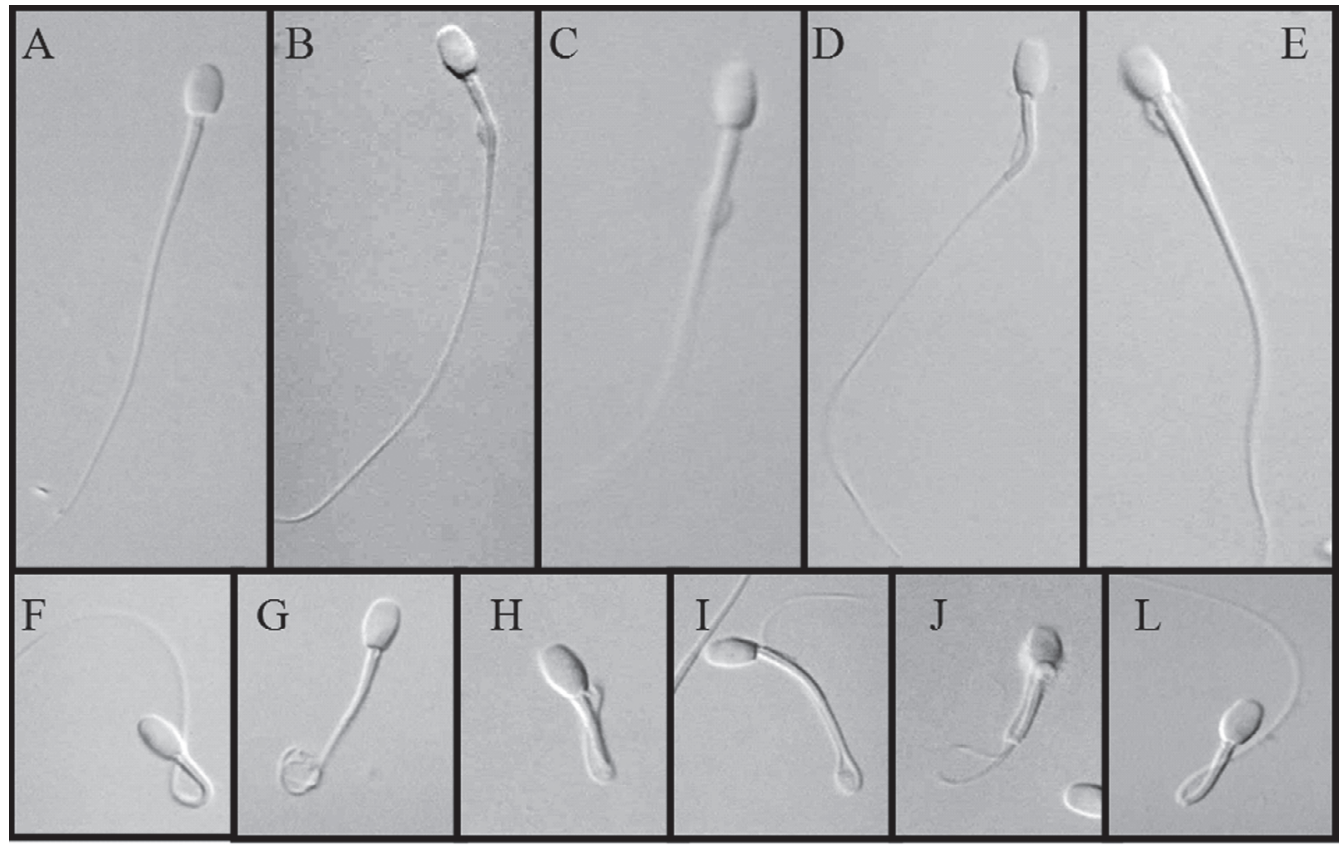

Figura 1 - Anormalidades morfológicas observadas no sêmen de Panthera leo: A) Normal ; B) e C) Gota citoplasmática distal; D) Peça intermediária dobrada com gota citoplasmática; E) Gota citoplasmática proximal; F) Peça intermediária dobrada; G) Cauda enrolada; H) Cauda fortemente enrolada; I), J) e L) Cauda fortemente dobrada. São Paulo, 2004. (sob aumento de 1000x)

animais têm maior prevalência de certas anormalidades. ${ }^{7}$ A precisa causa da gênese destas alterações espermáticas ainda não foi totalmente elucidada, mas a diminuição da variabilidade genética e a diminuição dos níveis de testosterona circulantes, criticamente necessários para a espermatogênese, têm sido relacionadas aos defeitos morfológicos dos espermatozóides. ${ }^{7,8}$

A literatura cita um percentual de 33,0 $\pm 6,3 \%$ de espermatozóides normais em leões africanos. ${ }^{7}$ Neste trabalho, obtivemos 44,45 $\pm 19,30 \%$ de espermatozóides morfologicamente normais. A proporção de pleiomorfismo espermático é relativamente alta se comparada aos animais domésticos, sendo esta uma característica seminal freqüente em muitas espécies de carnívoros silvestres, talvez até potencializada pelo isolamento geográfico e a endogamia. ${ }^{7,8}$ Além disso, as condições ambientais e de manejo aos quais estes animais estão submetidos podem influir na qualidade espermática apresentada, já que a temperatura ambiental, radiação, deficiência nutricional, alguns fármacos e compostos tóxicos, além de agentes bacterianos e virais podem ser prejudiciais à espermatogênese. ${ }^{9}$

Dentre as anormalidades morfológicas encontradas, a gota citoplasmática proximal e a peça intermediária dobrada com gota citoplasmática e peça intermediária dobrada, foram as mais observadas. A presença de gota citoplasmática proximal (Figura 1) pode ser decorrente de anormalidades na espermiogênese, sendo então associada às demais alterações morfológicas dos espermatozóides. ${ }^{10}$ Durante o processo fisiológico de maturação do espermatozóide no epidídimo, a gota citoplasmática deve migrar da porção proximal da peça intermediária para sua porção distal e então, finalmente destacar-se. ${ }^{10} \mathrm{~A}$ presença de espermatozóides com essa anormalidade morfológica pode, portanto, ser conseqüência de falha na maturação epididimal, degeneração e regeneração do epitélio seminífero, disfunções testiculares (por exemplo hipoplasia) ou epididimais ou aumento na demanda de sêmen decorrente de maior freqüência sexual. ${ }^{11} \mathrm{~A}$ persistência da gota citoplasmática distal não é 
considerada um sério problema de fertilidade, ao contrário da gota citoplasmática proximal. Neste processo, em algumas ocasiões a peça intermediária dobra-se em direção a gota, gerando a anormalidade peça intermediária dobrada com gota citoplasmática. ${ }^{10}$

A peça intermediária dobrada pode ser observada em animais que sofreram tratamentos com estradiol, ou que possuem uma baixa atividade tireoideana, ou ainda que passaram por febres efêmeras, insolação nos testículos ou qualquer outro tipo de estresse, ocasionando alterações no epitélio epididimal e prejuízo na maturação espermática. ${ }^{10} \mathrm{~A}$ cauda dobrada, peça intermediária dobrada ou ambas na mesma célula também podem ser oriundas de choque térmico durante a colheita ou ser decorrente de senilidade do sêmen, por falta de atividade sexual. ${ }^{11}$

Nos gatos domésticos (Felis catus), estudos sugerem que as células do epidídimo reconhecem e eliminam os espermatozóides com anormalidades em cabeça, acrossomo e peça intermediária. A maioria das anormalidades origina-se, portanto, no testículo, sendo que sua proporção diminui durante o trânsito epididimário. Em contrapartida, um aumento sutil, mas significante na quantidade de espermatozóides com caudas anormais sugere que esse defeito pode se originar no epidídimo, mais precisamente na sua porção distal, em decorrência de composição anormal do fluido epididimal. Essa característica também é observada em touros e suínos. ${ }^{12}$

As alterações morfológicas encontradas nas amostras foram, em ordem decrescente: -Defeitos Maiores: Gota Citoplasmática Proximal (11,22\%), Peça Intermediária Dobrada com Gota Citoplasmática (5,26\%), Peça Intermediária Dobrada $(5,09 \%)$, Superfície Anormal (3,89\%), Cauda Fortemente Enrolada (2,86\%), Cauda Fortemente Dobrada (2,37\%), Forma
Abortiva (2,00\%), Cabeça estreita (1,72\%), Peça Intermediária Filiforme (1,51\%), Cauda Dobrada com Gota Citoplasmática $(1,00 \%)$, Acrossomo (0,58\%), Microcefálico $(0,55 \%)$, Peça Intermediária Disforme (0,28\%), Cabeça Raquetiforme (0,28\%), Cabeça Lancetiforme $(0,24 \%)$, Cabeça Dupla $(0,21 \%)$, Cabeça Solta Anormal (0,21\%), Macrocefálico $(0,21 \%)$, Forma Teratológica (0,14\%), Cabeça Piriforme $(0,14 \%)$, Fratura de Cauda $(0,14 \%)$ e Cauda Dupla $(0,07 \%)$.

- Defeitos Menores: Cauda Dobrada (6,74\%), Gota Citoplasmática Distal (6,09\%), Cauda Enrolada (1,51\%), Cabeça Solta Normal (0, $52 \%$ e Inserção Abaxial da Peça Intermediária $(0,17 \%)$.

As anormalidades morfológicas mais observadas por Wildt (1987) foram gota citoplasmática, cauda fortemente enrolada e peça intermédiária dobrada e dobrada com gota citoplasmática. ${ }^{8}$

\section{Conclusão}

Os resultados obtidos puderam caracterizar o espermograma do grupo de leões africanos mantidos em cativeiro na Fundação Parque Zoológico de São Paulo. Estas informações são importantes não somente para avaliação do potencial reprodutivo do grupo estudado, como também para o desenvolvimento de técnicas de criopreservação de gametas desta espécie e espécies aparentadas.

\section{Agradecimento}

Os autores agradecem ao apoio da Fundação Parque Zoológico de São Paulo, permitindo o acesso aos animais. Este trabalho foi realizado com o imprescindível apoio do $\mathrm{CNPq}$, que concedeu Bolsa de Iniciação Científica do PIBIC.

\section{Spermogram of african lions (Panthera leo, Linnaeus, 1758) housed at Fundação Parque Zoológico de São Paulo}

\section{Abstract}

The aim of this sutdy was to analyse the spermogram of a group of captive African lions (Panthera leo), housed at the Fundação Parque
Key words:

African lion. Panthera leo. Semen. Spermogram. Electroejaculation. 
Zoológico de São Paulo, as a subject to avaluate the reproductive potential of the animals, an important aspect to apply artificial reproductive techniques. After chemical restraining, semen from 14 adult male lions was obtained by electroejaculation and the samples were examined right after the collection. The characteristics analyzed were: volume, $\mathrm{pH}$, general aspect, motility, progressive motility, spermatic motility index and concentration. One aliquot of the samples were fixed in saline-formol solution $10 \%$ and examined under Phase Contrast Microscopy for morphological evaluation, classifying in minor and major defects. The results were: volume $5,83+/-3,35 \mathrm{ml}$; concentration $11,62+/-14,51 \times 10^{6}$ sperm cells $/ \mathrm{ml}$; total motility 73,85 +/-11,02\% ; progressive motility3,35 +/- 0,63; spermatic motility index 70,42\%, pH 8,1 +/- 0,5; major defects 38,12 +/-19,41 \%; minor defects $17,43+/-10,36 \%$; total defects $55,55+/$ - $19,30 \%$. The more frequent major defects were: proximal droplet, bent midpiece with cytoplasmic droplet and bent midpiece. Bent tail was the most frequent minor defect observed.

\section{Referências}

1 GUIMARÃ̃S, M. A. de B. V. A aplicação de técnicas de reprodução assistida em animais silvestres mantidos em cativeiro. Revista Brasileira de Reprodução Animal, v. 25, n. 5 , p. 116-117, 2001.

2 GILMORE, J. A.; MCGANN, L. E.; ASHWORTH, E.; ACKER, J. P.; RAATH, J. P.; BUSH, M.; CRITSER, J. K. Fundamental cryobiology of selected African mammalian spermatozoa and its role in biodiversity preservation through the development of genome resource bank. Animal Reproduction Science, v. 53, p. 277-297, 1998.

3 SMUTS, G. L.; HANKS, J.; WHYTE, I. J. Reproduction and social organization of lions from the Kruger National Park. Carnivore, v. 1, n. 1, p. 17-28, 1978.

4 BROWN, J. L.; BUSH, M.; PACKER, C.; PUSEY, A. E.; MONFORT, S. L.; O 'BRIEN, S. J.; JANSSEN, D. L.; WILDT, D. E. Developmental changes in pituitarygonadal function in free-ranging lions (Panthera leo) of the Serengeti Plains and Ngorongoro Crater. Journal of Reproduction and Fertility, v. 91, p. 29-40, 1991

5 PUSEY, A. E.; PACKER, C. The evolution of sex-biased dispersal in lions. Behaviour, v. 101, p. 275-310, 1987.
6 BAUER, H.; NOWELL, K. Panthera leo. 2004 IUCN Red List of Threatened Species. Disponível em: < http:/ /www.redlist.org/>. Acesso em: 25 abr. 2005.

7 HOWARD, J. G. Semen collection and analysis in carnivores. In: FOWLER, M. E. Zoo and wild animal medicine current therapy. 3. ed. Philadelphia: W.B. Saunders, 1993. p. 390-399.

8 WILDT, D. E.; BUSH, M.; GOODROWE, K. L.; PACKER, C.; PUSEY, A. E.; BROWN, J. L.; JOSLIN, P. E.; O'BRIEN, S. J. Reproductive and genetic consequences of founding isolated lion populations. Nature, v. 329, p. 328-331, 1987.

9 CUPPS, P. T. Reproduction in domestic animals. $4^{\mathrm{a}}$ ed. San Diego: Academic Press, 1991. 670 p.

10 BARTH, A. D.; OKO, R. J. Abnormal morphology of bovine spermatozoa. Ames: lowa State University Press, 1989. $285 \mathrm{p}$.

11 ARTHUR, G. H.; NOAKES, D. E.; PEARSON, H. Veterinary reproduction and obstetrics. London: Baillière Tindal, 1989. $641 \mathrm{p}$.

12 AXNER, E.; LINDE-FORSBERG, C.; EINARSSON, S. Morphology and motility os sprematozoa from different region of the epididymal duct in the domestic cat. Theriogenology, v. 52, n. 5, p. 767-778, 1999. 